\title{
Response rates under varying probability of reinforcement'
}

J. FARMER AND W. N. SCHOENFELD

QUEENS COLLEGE OF THE CITY UNIVERSITY OF NEW YORK

Key-pecking performances of two pigeons were brought to steady response states under several values of probability of reinforcement. Mean post-reinforcement pause increased but response rates remained relatively invariant as reinforcement probability decreased.

We report a study of the effects of varying probability of reinforcement on key-pecking response rates for two pigeons. This parameter has been investigated by other workers both with individual subjects (Brandauer, 1958) and with groups (Sidley \& Schoenfeld, 1964), but response rates and post-reinforcement pauses have not previously been separated in the treatment of data. These measures do not necessarily co-vary, so that combining them into a single index may mask certain effects of the reinforcement probability variable. More important, the functions reported in one of those earlier studies (Brandauer, 1958) may have been biased by the failure to separate the acquisition phase from the asymptotic final levels toward which response rates move. Our present experimental design emphasizes the performance of individual organisms brought to steady response states under a wide range of values of reinforcement probability, with separate analyses of post-reinforcement pause and response rate data taken at each value.

\section{Mefhod}

Subjects. Two white Carneaux hen pigeons (No. 460 and No. 484), 6 to 8 years old, maintained at $80 \%$ of ad lib body weight throughout the experiment.

Apparatus. The experimental chamber was a Lehigh Valley Electronics pigeon box, model $1519 \mathrm{C}$, containing a pecking key as operandum. A minimum of $25 \mathrm{gm}$ of force was required for Microswitch closure. The key was transilluminated by a $1.8 \mathrm{log} \mathrm{ft} .-\mathrm{L}$ "white" diffused light. A BRS PP-1 probability generator, modified to produce reinforcement probabilities in 0.001 steps, was used to program probability of reinforcement which we notate as "P." The $P$ that is generated with this apparatus is (a) constant for any response and (b) independent of interresponse time. This means that the actual number of unreinforced responses that occur between reinforced ones can be predicted by the equation $P(N)=P(1-P)^{N-1}$ where $P$ is probability of reinforcement, $\mathrm{N}$ is the number of responses between reinforcements and $P(N)$ is the probability of that number. These reinforcement schedules that are generated when reinforcement is equally probable for any response are called "random ratio" in order to distinguish them from the more commonly employed "variable ratio" schedules wherein reinforcements occur after varying but preassigned numbers of unreinforced responses.

Procedure. After "shaping"' the key-pecking response (each reinforcer being 3-sec. access to mixed grain), each bird was exposed to $\mathrm{P}=1.0$ for a single experimental session of approximately 5-min. duration. Following this history of regular reinforcement, each $S$ was "shaped" over approximately the next 20 days so that its responding would be maintained at the lowest $P$ that was to be used in the study, namely, 0.002 . This was done by exposing each bird to progressively decreasing $P$ values, exposure to each $P$ being long enough (3-5 days) to ensure that they would continue to respond through the next drop in P. Following this history, the Ss were again exposed to the range of $P$ values (the range and values of $P$ employed were: $0.8,0.6,0.4,0.2,0.08,0.04,0.02,0.01,0.005,0.003$, 0.002) presented this time in mixed order for final data determination. Each bird remained at each $P$ for seven daily sessions, the reported data being taken from the last two of these sessions. The lengths of these final determinative sessions were $5 \mathrm{~min}$. at $0.8,0.6,0.4,0.2 ; 10 \mathrm{~min}$. at $0.08,0.04 ; 20 \mathrm{~min}$. at 0.02 ; $40 \mathrm{~min}$. at 0.01 ; and, $80 \mathrm{~min}$. at $0.005,0.003$, and 0.002 . The range of $P$ values used by Brandauer was 1.0 to .00167 ; by Sidley \& Schoenfeld, 1.0 to .0068 .

\section{Results and Discussion}

Figure 1 indicates that rate of responding does not vary in any systematic way over the range of $P$ that was used. This accords with the report of Sidley and Schoenfeld that no clearly systematic shift occurs across $P$ for group mean rates, although they argue that their function would have produced a maximum had they used still lower $P$ values than they did since,

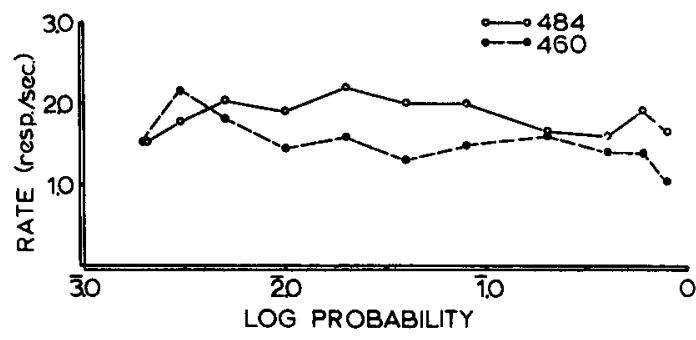

Fig. 1. Individual functions which relate rate of responding to probability of reinforcement, $P$. These rates were corrected by subtracting total reinforcer time and total post-reinforcement pause time from the criterion session lengths over which they were determined. 


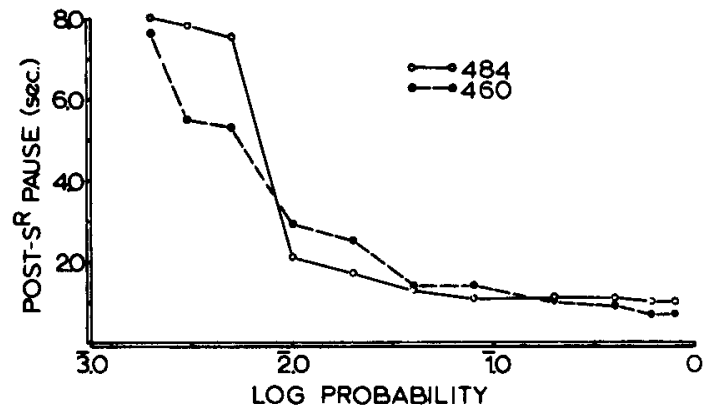

Fig. 2. Individual functions which relate mean post-reinforcement pause to probability of reinforcement. $P$. The mean pause was determined at each $P$ value by dividing the total time summated over both criterion sessions which accumulated between termination of 3-sec. reinforcer and occurrence of the first response following reinforcement by the number of reinforcers delivered during these sessions.

if $\mathbf{P}$ were small enough, responding could be presumed to extinguish.

The maximum in the probability rate function found by Brandauer in the region of $P=0.02$ was not reproduced in the present study, and this discrepancy may perhaps be attributed in part to differences between "shaping"'procedures of the two experiments. Brand- auer exposed his birds to successively decreasing values of $P$, taking his data from this systematic progression; our own procedure, as stated, was different from this. Further, Brandauer's computation of response rates, including post-reinforcement pauses, introduced the possibility of the Post- $\mathrm{S}^{\mathrm{R}}$ pause being the source of the maximum in his function, a possibility that takes on reality in the light of Fig. 2. This figure shows that Post-SR pause length begins to increase rapidly as $P$ goes below 0.02 , and it is in this region that Brandauer found overall rate (with Post-s ${ }^{R}$ included) beginning to decrease.

\section{References}

Brandauer, C. M. The effects of uniform probabilities of reinforcement upon the response rate of the pigeon. Unpublished doctoral dissertation, Columbia University, 1958.

Sidley, N. A., \& Schoenfeld, W. N. Behavior stability and response rates as functions of reinforcement probability on "random ratio" schedules. J. exp. Anal. Behav., 1964, 7, 281-283.

\section{Note}

1. This investigation was supported by Public Health Service Research Grant MH 08006, from the National Institute of Mental Health. Reprints may be obtained from the author, Department of Psychology, Queens College of the City University of New York, Flushing, N. Y., 11367. 